\title{
The impact of intra-abdominal pressure on perioperative outcomes in laparoscopic cholecystectomy: a systematic review and network meta-analysis of randomized controlled trials
}

\author{
Amit D. Raval ${ }^{1} \cdot$ Sohan Deshpande ${ }^{2} \cdot$ Maria Koufopoulou $^{2} \cdot$ Silvia Rabar $^{2} \cdot$ Binod Neupane $^{3} \cdot$ Ike Iheanacho $^{2}$. \\ Lori D. Bash ${ }^{1}$. Jay Horrow ${ }^{4}$. Thomas Fuchs-Buder ${ }^{5}$
}

Received: 23 December 2019 / Accepted: 26 March 2020 / Published online: 6 April 2020

(c) The Author(s) 2020

\begin{abstract}
Background Laparoscopic cholecystectomy involves using intra-abdominal pressure (IAP) to facilitate adequate surgical conditions. However, there is no consensus on optimal IAP levels to improve surgical outcomes. Therefore, we conducted a systematic literature review (SLR) to examine outcomes of low, standard, and high IAP among adults undergoing laparoscopic cholecystectomy.

Methods An electronic database search was performed to identify randomized controlled trials (RCTs) that compared outcomes of low, standard, and high IAP among adults undergoing laparoscopic cholecystectomy. A Bayesian network meta-analysis (NMA) was used to conduct pairwise meta-analyses and indirect treatment comparisons of the levels of IAP assessed across trials.

Results The SLR and NMA included 22 studies. Compared with standard IAP, on a scale of 0 (no pain at all) to 10 (worst imaginable pain), low IAP was associated with significantly lower overall pain scores at $24 \mathrm{~h}$ (mean difference [MD]: -0.70 ; 95\% credible interval [CrI]: $-1.26,-0.13$ ) and reduced risk of shoulder pain $24 \mathrm{~h}$ (odds ratio [OR] 0.24; 95\% CrI 0.12, 0.48 ) and $72 \mathrm{~h}$ post-surgery (OR $0.22 ; 95 \% \mathrm{CrI} 0.07,0.65$ ). Hospital stay was shorter with low IAP (MD: -0.14 days; $95 \%$ $\mathrm{CrI}-0.30,-0.01)$. High IAP was not associated with a significant difference for these outcomes when compared with standard or low IAP. No significant differences were found between the IAP levels regarding need for conversion to open surgery; post-operative acute bleeding, pain at $72 \mathrm{~h}$, nausea, and vomiting; and duration of surgery.

Conclusions Our study of published trials indicates that using low, as opposed to standard, IAP during laparoscopic cholecystectomy may reduce patients' post-operative pain, including shoulder pain, and length of hospital stay. Heterogeneity in the pooled estimates and high risk of bias of the included trials suggest the need for high-quality, adequately powered RCTs to confirm these findings.
\end{abstract}

Keywords Cholecystectomy $\cdot$ Laparoscopy $\cdot$ Neuromuscular blockade $\cdot$ Post-operative intra-abdominal pressure . Pneumoperitoneum

Electronic supplementary material The online version of this article (https://doi.org/10.1007/s00464-020-07527-2) contains supplementary material, which is available to authorized users.

Thomas Fuchs-Buder

t.fuchs-buder@chru-nancy.fr

1 Center for Observational and Real-World Evidence, Merck \& Co., Inc, Kenilworth, NJ, USA

2 Evidence Synthesis, Modeling, and Communication, Evidera Inc, London, UK
A standard practice in laparoscopic cholecystectomy is to use carbon dioxide to inflate the peritoneal cavity to form a pneumoperitoneum that creates adequate working space for operating. However, there is no consensus on the optimal

3 Evidence Synthesis, Modeling, and Communication, Evidera Inc, Montreal, Canada

4 Merck \& Co., Inc., Kenilworth, NJ, USA

5 Department of Anesthesiology \& Critical Care, Brabois University Hospital, University de Lorraine, CHRU Nancy, 7 allée du Morvan, 54511 Vandoeuvre-les-Nancy, France 
intra-abdominal pressure (IAP) for such a pneumoperitoneum, and levels that are too low or high may be associated with key limitations. For instance, very low IAP may restrict the surgeon's visual field and the space for surgical instruments; conversely, increased IAP could result in cardiopulmonary complications and post-operative pain requiring management with analgesics $[1,2]$. Therefore, there is a need for a clear understanding of where to set IAP levels to improve overall surgical outcomes. A key additional consideration is induced muscle paralysis that is often used as part of anesthesia. Specifically, deep neuromuscular block (dNMB) allows for complete relaxation of the abdominal wall musculature and immobilizes the diaphragm, effects that facilitate reduction of the insufflation pressure without compromising the surgical field of vision in laparoscopic abdominal surgeries [3, 4]. However, dNMB has the potential disadvantage of not being reversible by some conventional anti-cholinesterase agents (neostigmine, pyridostigmine), although the introduction of a novel, dNMB-reversing agent to anesthetic practice has allowed more frequent use of the technique $[5,6]$.

Available evidence to inform practice in this clinical setting includes two systematic literature reviews (SLRs) of randomized controlled trials (RCTs), published in 2013 [7] and 2014 [7, 8]. These reviews suggested that, compared with standard IAP, low IAP pneumoperitoneum for laparoscopic cholecystectomy is associated with significantly reduced post-operative pain (including referred shoulder pain [7]) and analgesic use post-surgery [7, 8]. However, the impact of low IAP on operating times, hospital stays, and other surgical outcomes is not clear. Also, a Cochrane review published around the same time [1] concluded there was no evidence to support using low IAP pneumoperitoneum (defined as $<12 \mathrm{mmHg}$ ), compared with standard IAP (defined as 12-16 mmHg), in low-risk surgical patients undergoing planned laparoscopic cholecystectomy. Crucially, no published SLRs have compared the outcomes of low, standard, and high IAP in laparoscopic cholecystectomy in a network meta-analysis (NMA) or used standardized definitions of IAP levels to ensure comparability of data across the studies included in meta-analyses. In light of these data gaps and the availability of additional RCTs beyond those included in existing SLRs on this topic, we conducted an SLR and NMA of RCTs to investigate the impact of different levels of IAP (in clinically well-defined categories of "low," "standard," and "high" IAP) on surgical, patientreported, and resource use outcomes after laparoscopic cholecystectomy.

\section{Materials and methods}

This SLR was conducted in accordance with the quality standards recommended by the Preferred Reporting Items for Systematic Reviews and Meta-Analyses (PRISMA) statement [9] and the Cochrane Handbook for Systematic Reviews [10].

\section{Criteria for inclusion in the SLR}

The SLR included RCTs that assessed surgical, patientreported, and resource use outcomes associated with using various levels of IAP to produce a pneumoperitoneum in adults undergoing laparoscopic cholecystectomy. Specifically, studies were eligible if they compared at least two of the following levels of IAP: low $(<12 \mathrm{mmHg})$, standard (12-14 mmHg), and high ( $\geq 15 \mathrm{mmHg})$. These IAP categories were chosen on clinical grounds, after examination of the data available in the published literature, and in consultation with expert clinicians. The pre-specified outcomes of interest for consideration in the SLR represented clinically important safety, patient-centered, and efficiency metricsconversion to open surgery represents a failure of chosen approach, impacting costs and patient comfort; post-operative pain (general and specifically shoulder pain, each at 24 and $72 \mathrm{~h}$ post-surgery) affects patient satisfaction and potential safety issues from its treatment; acute bleeding, a safety and cost issue; post-operative nausea or vomiting degrades safety, efficiency, and patient satisfaction; the efficiency metrics of duration of surgery; and length of inpatient stay.

\section{Database searches}

To identify publications evaluating laparoscopic abdominal surgery in adults, the following electronic databases were searched from their dates of inception to September 14, 2018: Embase, MEDLINE, and MEDLINE In-Process via PubMed; the Cochrane Library; the Cochrane Central Register of Controlled Trials (CENTRAL); and the Database of Abstracts of Reviews of Effects (DARE). The searches were not restricted by using terms specific to "cholecystectomy"; this was to capture studies on broader categories of laparoscopic abdominal surgery that might have included separate results for any cholecystectomy subgroups. The searches were limited to English-language publications, studies in humans, and RCTs; in addition, the searches were designed to identify relevant SLRs of RCTs (published since 2016) so that the bibliographies of these reviews could be checked for RCTs not found directly by the database searches. No geographical restrictions were applied in the searches. Full details of the search strings used are provided in Appendix Table 1 in the Supplementary Material. 
A gray literature search for relevant RCTs was also conducted in selected conference proceedings from 2017 and 2018 (specifically for the American Society of Anesthesiologists; the European Society of Anesthesiology; and the International Anesthesia Research Society) and registries of ongoing clinical trials (namely, clinicaltrials.gov and World Health Organization International Clinical Trials Registry Platform).

\section{Study selection and extraction}

Two independent researchers screened publications (MK, $\mathrm{SR}$ ); disagreements were resolved by a third, senior investigator (SD). Pre-specified data of interest on study design, population baseline characteristics, interventions/comparators, and outcomes were extracted from included studies by one researcher (MK or SR), and independently validated by a second researcher (SD). Each included study was assessed using the Cochrane Risk of Bias tool for RCTs [10] and designated as having a low, moderate, or high risk of bias.

\section{Feasibility assessment of indirect comparison}

We conducted feasibility assessment on the studies identified in the SLR to examine the populations, interventions/comparators, and outcome assessments across the trials. With a view to decrease heterogeneity, analyses were undertaken for trials on patients undergoing laparoscopic cholecystectomy, which also improved transitivity (with respect to disease and surgical procedure). For each possible analysis scenario, all potentially eligible trials were assessed with respect to distributions of possible treatment effect modifiers and covariates to assess whether they were sufficiently similar for a valid indirect comparison; an appropriate decision was then made to include or exclude each trial. After the feasibility assessment, none of the evidence networks had direct and indirect evidence. Evidence was available for comparisons of low vs. high or low vs. standard IAP (Fig. 1). Therefore, disagreement (inconsistency) between direct and indirect evidence was not assessed.

\section{Statistical analysis}

For each outcome of interest, the comparative effects of low, standard, and high IAP were assessed using a Bayesian NMA (when all three IAP levels were included in the evidence network) or Bayesian meta-analysis (MA) (when only two IAP levels were included in the network; i.e., when RCTs provided evidence for only one comparison). Classical/frequentist direct MA for a comparison was also performed as a sensitivity analysis. Where possible, a random-effects (RE) model was used as the primary analytical approach, with a fixed-effect (FE) model used in a sensitivity analysis to assess the impact of heterogeneity on the primary results. However, an FE model was used as for primary analysis if only one study was available for each head-tohead comparison, or where event rates for a binary outcome were very low.

In a Bayesian NMA or MA conducted using the RE model, the prior distribution used for between-study standard deviation $(\tau)$ was uniform for a dichotomous $(0,1)$ outcome and for a continuous outcome $(0, b)$, where " $b$ " was approximately twice the average standard deviation, with mean or median data. In each Bayesian NMA, the first 100,000 samples from Monte Carlo Markov Chain (MCMC) simulation were discarded and another 100,000 samples were saved for posterior inference. Convergence to posterior distribution of each parameter (effects and heterogeneity, where applicable) of interest was achieved in statistical tests and graphical examination. For each comparison, the pooled estimate of a relative effect (e.g., mean difference [MD] for a continuous outcome and odds ratio [OR] for a binary outcome) and corresponding $95 \%$ credible intervals $(\mathrm{CrI})$ were obtained to summarize these posterior samples. An MD with the $\mathrm{CrI}$ excluding 0 or an OR with $\mathrm{CrI}$ excluding 1 was considered statistically significant (from an interpretation perspective). The probability of each treatment being better than any other comparator treatment was also computed as the probability of $\mathrm{MD}<0$ or $\log (\mathrm{OR})<0$ for a bad outcome (e.g., length of surgery or conversion to open surgery) and vice versa. The
Fig. 1 Network diagrams. IAP intra-abdominal pressure, $M A$ meta-analysis, NMA network meta-analysis

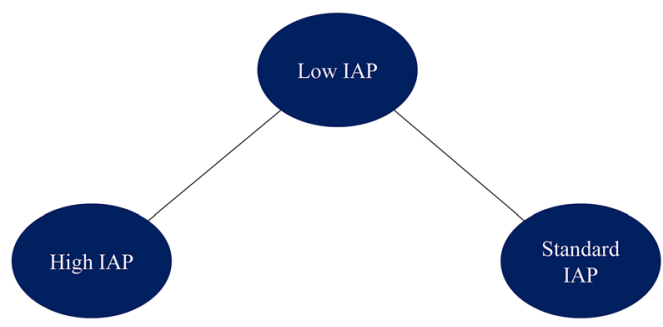

Bayesian NMA network

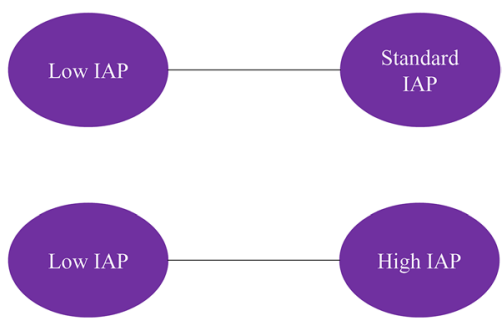

MA comparisons 
Bayesian NMAs were performed in OpenBUGS (version 3.2.3) via $R$ (version 3.5.1).

For each outcome, the heterogeneity in the estimates of an effect between studies for a pairwise comparison was examined by computing $\mathrm{I}^{2}$ (the percentage of between-study heterogeneity beyond chance) [11], estimating betweenstudy variance $\left(\tau^{2}\right)$ using restricted maximal likelihood, and computing the p-value in the Cochran's Q test of homogeneity. These pairwise meta-analyses were performed using the “metafor" package in R (version 3.5.1).

\section{Results}

The SLR searches generated 3924 unique records, of which 22 were ultimately eligible for and included in the review (Fig. 2). Studies that reported duration of surgery only as a baseline characteristic $(n=18)$ without assessing any post-operative outcomes or presenting extractable data $(n=5)$ were excluded.

Table 1 describes the RCTs included in the SLR. The studies were carried out in Asia $(n=14)$, Europe $(n=6)$, and Africa $(n=2)$, and involved between 20 and 148

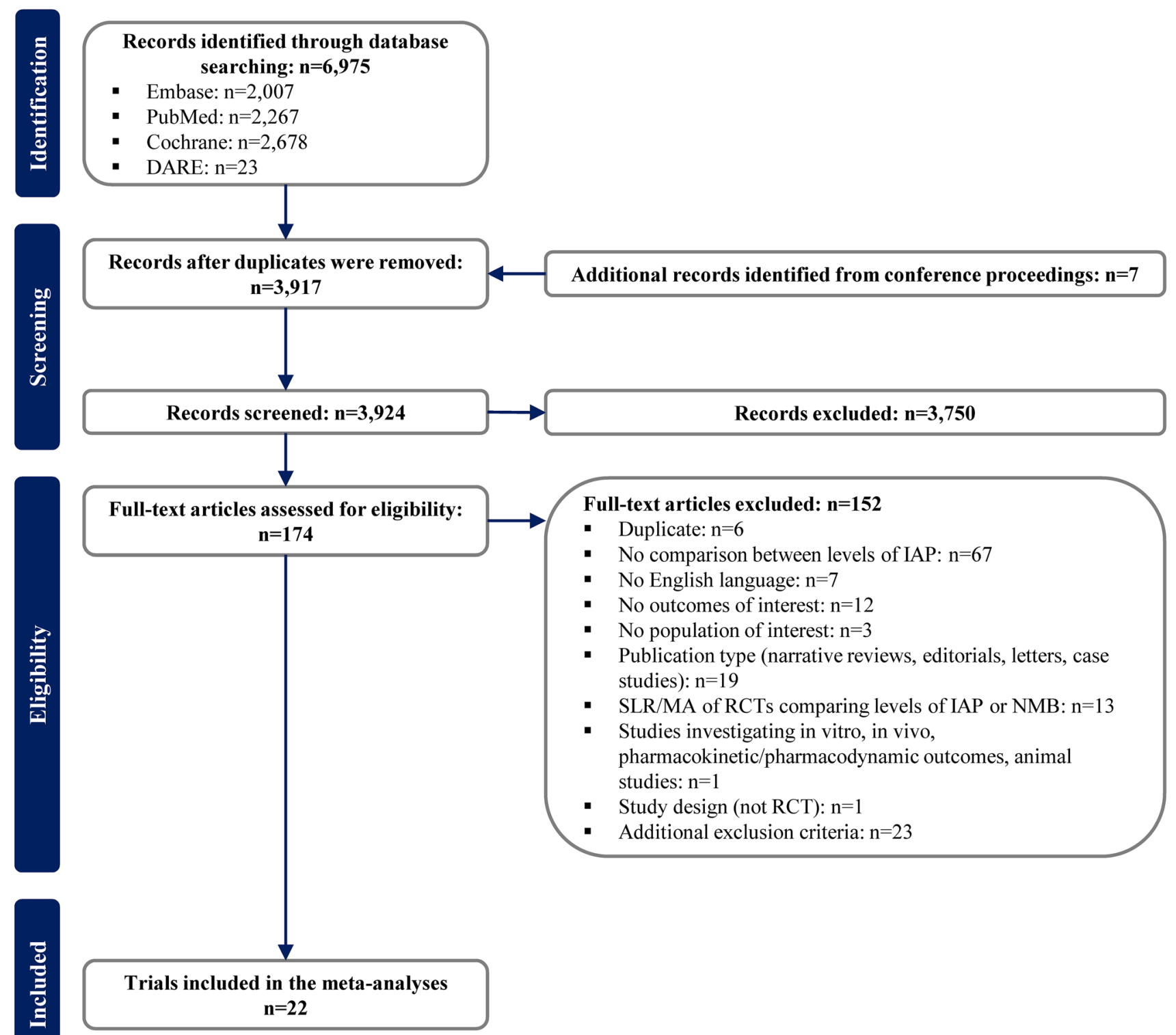

Fig. 2 PRISMA diagram. DARE Database of Abstracts of Reviews and Effects, IAP intra-abdominal pressure, $M A$ meta-analysis, $N M B$ neuromuscular block, $R C T$ randomized controlled trial, SLR systematic literature review 
Table 1 Characteristics of studies included in the SLR

\begin{tabular}{|c|c|c|c|c|c|c|}
\hline Author and year & $\begin{array}{l}\text { Study arm based on } \\
\text { proposed IAP categori- } \\
\text { zation }\end{array}$ & Study arm (mmHg) & Country & N Randomized & $\mathrm{N}$ completed & Who was blinded? \\
\hline Barczynski (2003) [15] & Low vs. Standard & 7 vs. 12 & Poland & 148 & 148 & $\mathrm{P}$ \\
\hline Bhattacharjee (2017) [29] & Low vs. Standard & $9-10$ vs. 14 & India & 80 & 80 & $\mathrm{~A}+\mathrm{P}$ \\
\hline Celik (2010) [16] & Low vs. Standard & 8 vs. 12,14 & Turkey & 64 & 60 & NR \\
\hline Chok (2006) [17] & Low vs. Standard & 7 vs. 12 & China & 40 & 40 & $\mathrm{~N}$ \\
\hline Dexter (1999) [26] & Low vs. High & 7 vs. 15 & UK & 23 & 20 & NR \\
\hline Ekici (2009) [27] & Low vs. High & 7 vs. 15 & Turkey & 70 & 52 & A \\
\hline Esmat (2006) [23] & Low vs. High & 10 vs. 14 & Egypt & 109 & 109 & NR \\
\hline Ibraheim (2006) [30] & Low vs. Standard & $6-8$ vs. $12-14$ & $\begin{array}{l}\text { NR (assumed } \\
\text { Saudi Ara- } \\
\text { bia) }\end{array}$ & 20 & 20 & NR \\
\hline Joshipura (2009) [18] & Low vs. Standard & 8 vs. 12 & India & 26 & 26 & $\mathrm{P}+\mathrm{S}$ \\
\hline Kandil (2010) [19] & Low vs. Standard & 8,10 vs. 12,14 & Egypt & 100 & 100 & NR \\
\hline Kanwer (2009) [12] & Low vs. Standard & 10 vs. 14 & India & 60 & 55 & NR \\
\hline Koc (2005) [20] & Low vs. High & 10 vs. 15 & Turkey & 53 & 50 & A \\
\hline Ko-iam (2016) [13] & Low vs. Standard & 7 vs. 14 & Thailand & 120 & 115 & $\mathrm{~A}+\mathrm{P}+\mathrm{S}$ \\
\hline Meijer (1997) [14] & Low vs. High & 5 vs. 15 & Netherlands & 20 & 18 & NR \\
\hline Perrakis (2003) [28] & Low vs. High & 8 vs. 15 & Greece & 40 & 40 & $\mathrm{P}+\mathrm{S}$ \\
\hline Sandhu (2009) [21] & Low vs. Standard & 7 vs. 14 & Thailand & 140 & 140 & $\mathrm{~N}$ \\
\hline Sarli (2000) [24] & Low vs. Standard & 9 vs. 13 & Italy & 94 & 90 & $\mathrm{P}+\mathrm{A}$ \\
\hline Singla (2014) [22] & Low vs. Standard & $7-8$ vs. $12-14$ & India & 100 & 100 & NR \\
\hline Vijayaraghavan (2014) [31] & Low vs. Standard & 8 vs. 12 & India & 44 & 43 & $\mathrm{P}+\mathrm{A}$ \\
\hline Wallace (1997) [37] & Low vs. High & 7.5 vs. 15 & UK & 40 & 40 & $\mathrm{P}+\mathrm{A}$ \\
\hline Yasir (2012) [25] & Low vs. Standard & 8 vs. 14 & India & 100 & 100 & NR \\
\hline Zaman (2015) [38] & Low vs. Standard & $7-8$ vs. $12-14$ & India & 50 & 50 & NR \\
\hline
\end{tabular}

$A$ assessors of outcomes, IAP intra-abdominal pressure, $N$ nurse, $N R$ not reported, $P$ patient, $S$ Surgeon, $U K$ United Kingdom

patients each. Application of the low, standard, or high IAP categories defined for collation of data across the trials showed that nine studies compared low with standard IAP and four compared low with high IAP. No trial compared standard and high IAP levels. Five studies were single-blinded, six were double-blinded, one was tripleblinded, and six did not report their blinding status. Of the studies that reported blinding details, patients were most frequently blinded (in eight studies), followed by the outcome assessors (in seven studies), and the surgeons (in three studies).

Table 2 describes the baseline characteristics of the population in each included study. In general, these variables were well balanced between the intervention and comparator groups within the RCTs. The mean age of patients across studies ranged from 35 to 59 years. All trials enrolled patients with an American Society of Anesthesiologists (ASA) status ranging from I to III. Quality assessment of the included studies (using the Cochrane Risk of Bias tool) suggested that $68 \%$ had a high risk of bias, $23 \%$ a moderate risk, and 9\% a low risk (Fig. 3). When the individual bias domains of attrition, detection, performance, and selection were considered, the proportion of the included studies rated as having a high risk of bias ranged from 18 to $45 \%$.

\section{Surgical outcomes}

Three studies [12-14] that reported on the need to convert laparoscopic surgery to open surgery, were included in a Bayesian NMA of this outcome. The analysis (conducted using an FE model because of very low rates of the event of interest) showed no statistically significant differences between the three IAP levels with respect to then need to convert to open surgery (Fig. 4).

\section{Patient-reported outcomes}

To assess post-operative pain, most of the included RCTs used a visual analog scale ranging from 0 to 10 , where 0 indicated "no pain at all" and 10 "worst imaginable pain." For studies that used a scale from 0 to 100 , we converted the data to a 0 to 10 scale before they were included in the meta-analyses. 
Table 2 Baseline characteristics of the included RCTs

\begin{tabular}{|c|c|c|c|c|c|c|}
\hline Author and year & IAP level & $\mathrm{N}$ at baseline & Mean age (SD) [years] & Male $(\%)$ & Mean BMI (SD) $\left[\mathrm{kg} / \mathrm{m}^{2}\right]$ & $\begin{array}{l}\text { ASA physical } \\
\text { status classifi- } \\
\text { cation }(\%)\end{array}$ \\
\hline \multirow[t]{2}{*}{ Barczynski (2003) [15] } & Low & 74 & $48.2(12.1)$ & 12.2 & $27.5(3.2)$ & $\begin{array}{l}\text { I: } 70.3 \\
\text { II: } 29.7\end{array}$ \\
\hline & Standard & 74 & $47.8(12.6)$ & 13.5 & $27.1(3.3)$ & $\begin{array}{l}\text { I: } 63.5 \\
\text { II: } 36.5\end{array}$ \\
\hline \multirow[t]{2}{*}{ Bhattacharjee (2017) [29] } & Low & 40 & $37.9(9.3)$ & NR & $24.7(2.8)$ & ASA I-II* \\
\hline & Standard & 40 & $35.3(11.2)$ & NR & $25.2(2.6)$ & ASA I-II* \\
\hline \multirow[t]{3}{*}{ Celik (2010) [16] } & Low & 20 & $42.9(10.8)$ & 0 & NR & ASA I-II* \\
\hline & Standard & 20 & $43.8(9.9)$ & 0 & NR & ASA I-II* \\
\hline & Standard & 20 & $45.3(8.6)$ & 0 & NR & ASA I-II* \\
\hline \multirow[t]{2}{*}{ Chok (2006) [17] } & Low & 20 & $47.6(10.0)$ & 40 & NR & $\begin{array}{l}\text { I: } 95 \\
\text { II: } 90\end{array}$ \\
\hline & Standard & 20 & $47.2(11.0)$ & 40 & NR & $\begin{array}{l}\text { I: } 5 \\
\text { II: } 10\end{array}$ \\
\hline \multirow[t]{2}{*}{ Ibraheim (2006) [30] } & Low & 10 & $47.2(6.6)$ & 30 & $27.0(1.9)$ & $\begin{array}{l}\text { I: } 10 \\
\text { II: } 90\end{array}$ \\
\hline & Standard & 10 & $49.9(10.5)$ & 30 & $26.9(2.1)$ & $\begin{array}{l}\text { I: } 60 \\
\text { II: } 40\end{array}$ \\
\hline \multirow[t]{2}{*}{ Joshipura (2009) [18] } & Low & 14 & 57 (NR) & 64 & $27.5(1.0)$ & ASA I-II* \\
\hline & Standard & 12 & 58 (NR) & 50 & $26(1.4)$ & ASA I-II* \\
\hline \multirow[t]{2}{*}{ Kandil (2010) [19] } & Low & 100 & $42.4(10.7)(18-61)$ & 38 & NR & ASA I-II* \\
\hline & Standard & 30 & NR & NR & NR & NR \\
\hline \multirow[t]{2}{*}{ Kanwer (2009) [12] } & Low & 30 & NR & NR & NR & NR \\
\hline & Standard & 30 & NR & NR & NR & NR \\
\hline \multirow[t]{2}{*}{ Ko-iam (2016) [13] } & Low & 60 & $51.0(13.3)$ & 18.3 & $24.6(4.1)$ & $\begin{array}{l}\text { I: } 28.3 \\
\text { II: } 71.7\end{array}$ \\
\hline & Standard & 60 & $52.8(12.1)$ & 30 & $24.3(3.4)$ & $\begin{array}{l}\text { I: } 41.7 \\
\text { II: } 58.3\end{array}$ \\
\hline \multirow[t]{2}{*}{ Sandhu (2009) [21] } & Low & 70 & $54(12.9)(27-78)$ & 12.9 & NR & ASA I-II* \\
\hline & Standard & 70 & $55.2(13.2)(20-84)$ & 25.7 & NR & ASA I-II* \\
\hline \multirow[t]{2}{*}{ Sarli (2000) [24] } & Low & 46 & Mean $49.3(22-83)$ & 28.3 & NR & ASA I-II* \\
\hline & Standard & 44 & Mean 47.7 (27-78) & 25 & NR & ASA I-II* \\
\hline \multirow[t]{2}{*}{ Singla (2014) [22] } & Low & 50 & $50.6(14.0)$ & 24 & NR & NR \\
\hline & Standard & 50 & $53.8(13.8)$ & 40 & NR & NR \\
\hline \multirow[t]{2}{*}{ Vijayaraghavan (2014) [31] } & Low & 22 & 44.5 (IQR: 31.5-51.5) & 36.4 & NR & $\begin{array}{l}\text { I: } 63.6 \\
\text { II: } 66.7\end{array}$ \\
\hline & Standard & 21 & 40 (IQR: 31.5-49.5) & 42.9 & NR & $\begin{array}{l}\text { I: } 36.4 \\
\text { II: } 33.3\end{array}$ \\
\hline \multirow[t]{2}{*}{ Yasir (2012) [25] } & Low & 50 & NR & NR & NR & NR \\
\hline & Standard & 50 & NR & NR & NR & NR \\
\hline \multirow[t]{2}{*}{ Zaman (2015) [38] } & Low & 25 & NR & NR & NR & ASA I-II* \\
\hline & Standard & 25 & NR & NR & NR & ASA I-II* \\
\hline \multirow[t]{2}{*}{ Dexter (1999) [26] } & Low & 10 & Mean: 48 (range: 19-72) & 30 & Mean: 25.4 (range: $18.1-32.2$ ) & ASA I-II* \\
\hline & High & 10 & Mean: 56 (range: $27-71$ ) & 40 & Mean: 27 (range: 20.1-30.9) & ASA I-II* \\
\hline \multirow[t]{2}{*}{ Ekici (2009) [27] } & Low & 20 & $52.2(10.1)$ & 10 & $28.5(4.8)$ & ASA I-II* \\
\hline & High & 32 & $49.3(12.6)$ & 18.8 & $28.4(5.1)$ & ASA I-II* \\
\hline \multirow[t]{3}{*}{ Esmat (2006) [23] } & Low & 37 & 47.8 (NR) & 27 & NR & ASA I-II* \\
\hline & Low & 38 & 45.8 (NR) & 26.3 & NR & ASA I-II* \\
\hline & High & 34 & 46.6 (NR) & 26.5 & NR & ASA I-II* \\
\hline \multirow[t]{2}{*}{ Koc (2005) [20] } & Low & 25 & $46.3(15.5)$ & 12 & NR & ASA I-III* \\
\hline & High & 25 & $47.9(15.2)$ & 24 & NR & ASA I-III* \\
\hline
\end{tabular}


Table 2 (continued)

\begin{tabular}{|c|c|c|c|c|c|c|}
\hline Author and year & IAP level & $\mathrm{N}$ at baseline & Mean age (SD) [years] & Male $(\%)$ & Mean BMI (SD) $\left[\mathrm{kg} / \mathrm{m}^{2}\right]$ & $\begin{array}{l}\text { ASA physical } \\
\text { status classifi- } \\
\text { cation }(\%)\end{array}$ \\
\hline \multirow[t]{2}{*}{ Meijer (1997) [14] } & Low & 9 & $(22-50)$ & 11 & NR & ASA I-II* \\
\hline & High & 9 & $(30-52)$ & 22 & NR & ASA I-II* \\
\hline \multirow[t]{2}{*}{ Perrakis (2003) [28] } & Low & 20 & $58.5(33-79)$ & 35 & $26.4(21.2-34.3)$ & $\begin{array}{l}\text { I: } 60 \\
\text { II: } 40\end{array}$ \\
\hline & High & 20 & $55(30-79)$ & 15 & $25.3(19.8-43.6)$ & $\begin{array}{l}\text { I: } 65 \\
\text { II: } 35\end{array}$ \\
\hline \multirow[t]{2}{*}{ Wallace (1997) [37] } & Low & 20 & Median: 59 (IQR: 52-64) & 30 & $\begin{array}{l}\text { Median: } 26.4 \text { (IQR: } 24.8- \\
\text { 28.4) }\end{array}$ & NR \\
\hline & High & 20 & Median: 56 (IQR: 50-64) & 20 & $\begin{array}{l}\text { Median: } 25.9 \text { (IQR: } 23.1- \\
29.5)\end{array}$ & NR \\
\hline
\end{tabular}

* Specific \% is not reported

ASA American Society of Anesthesiologists, $B M I$ body mass index, IAP intra-abdominal pressure, IQR interquartile range, $N R$ not reported, $S D$ standard deviation

\section{SUMMARY OF QUALITY ASSESSMENT BY DOMAIN}

OVERALL RISK OF BIAS

OTHER BIAS

REPORTING BIAS

ATTRITION BIAS

DETECTION BIAS

PERFORMANCE BIAS

SELECTION BIAS

\section{$\square$ Low $\square$ Moderate $\square$ High}

$\begin{array}{lll}9 \% & 23 \% & 68 \%\end{array}$

$\mathbf{5 0 \%} \quad 50 \%$

$9 \%$ $91 \%$

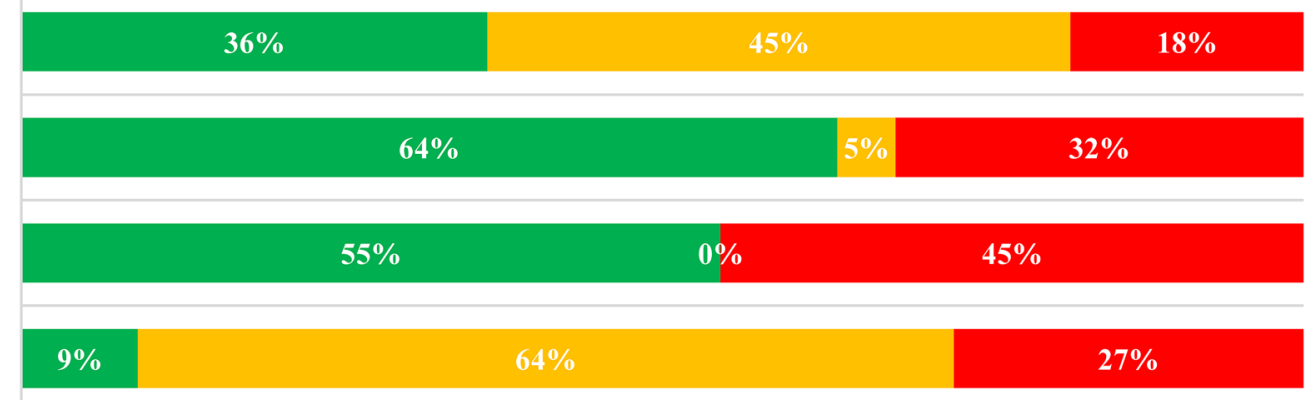

Fig. 3 Quality assessment by Cochrane Risk of Bias tool

Nine studies [12, 15-22] that reported on post-operative pain $24 \mathrm{~h}$ post-surgery were included in the Bayesian NMA (Fig. 5A). The results of this analysis showed that when compared with standard IAP, low IAP was associated with significantly lower pain scores at $24 \mathrm{~h}$ (MD: $-0.70 ; 95 \%$ $\mathrm{CrI}-1.26,-0.13, n=8$ studies). There was no significant difference between low and high IAP with regard to this outcome ( $n=1$ study). No studies directly compared standard and high IAP, but a Bayesian NMA showed a non-statistically significant difference between the levels (high between-study heterogeneity: $I^{2}=93.3 \%$ ).

Three studies $[15,17,19]$ reported on post-operative pain $72 \mathrm{~h}$ post-surgery and were included in a Bayesian MA (Fig. 5B). The analysis suggested no significant difference between low and standard IAP for the severity of this outcome, with high between-study heterogeneity in frequentist meta-analysis $\left(I^{2}=94.9 \%\right)$.

Six studies $[12,17,19,23-25]$ reported on the dichotomous outcome of post-operative shoulder pain $24 \mathrm{~h}$ after 


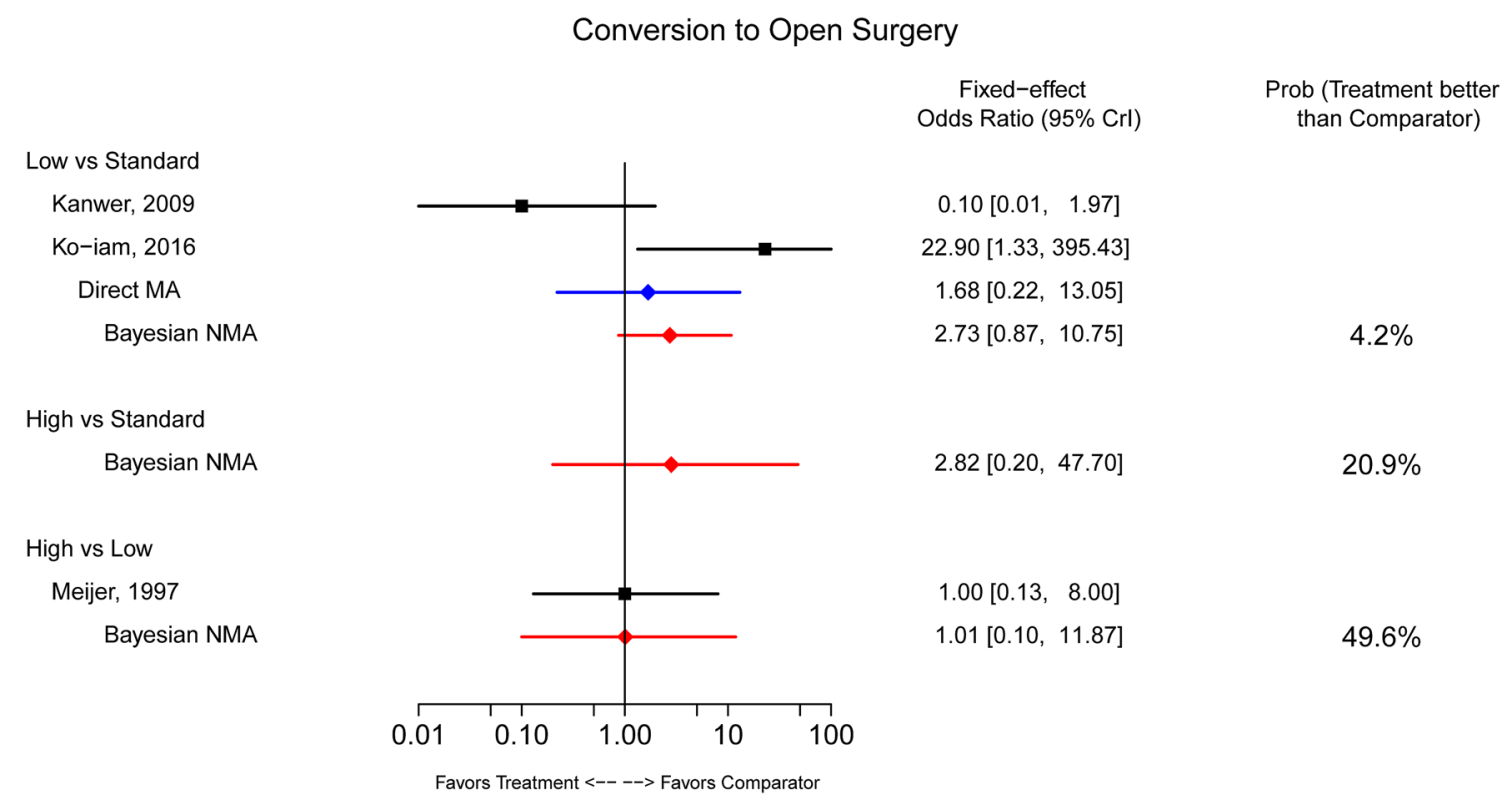

Fig. 4 Surgical conditions outcomes. $C r I$ credible interval, $M A$ meta-analysis, $N M A$ network meta-analysis, Prob probability

laparoscopic cholecystectomy (Fig. 5C). A Bayesian MA showed that, compared with standard IAP, low IAP was associated with a statistically significantly reduced risk of shoulder pain (OR 0.24; 95\% CrI 0.12, 0.48) $\left(I^{2}=89.9 \%\right)$. Two studies also reported on shoulder pain $72 \mathrm{~h}$ after surgery $[17,19]$ (Fig. 5D) and were included in a Bayesian MA. The analysis showed that, compared with standard IAP, low IAP was associated with a statistically significantly reduced risk of such pain (OR 0.22; 95\% CrI 0.07, 0.65).

Four studies [22, 26-28] reported on acute post-operative bleeding (Fig. 5E) and were included in a Bayesian NMA. No difference was observed among the IAP levels with respect to this outcome. Only two studies [22, 28] reported on post-operative nausea and vomiting (Fig. 5F). One study compared low to standard IAP; the other compared low to high IAP. The FE analysis of these limited data suggested no difference in the likelihood of post-operative nausea and vomiting among the three levels of IAP.

\section{Healthcare resource utilization}

Seventeen RCTs [12-18, 20, 21, 23-27, 29-31] were included in the NMA that assessed duration of surgery (Fig. 6A). There was considerable heterogeneity across the studies and, overall, no significant difference between IAP levels was observed in the RE analysis. Six studies [15, 18, 21, 23-25] reported on length of inpatient stay (days) (Fig. 6B). Bayesian NMA suggested that low IAP resulted in a shorter stay (MD - 0.14 days; $95 \% \mathrm{CrI}-0.30,-0.01$ ) compared with standard IAP. No studies reported comparisons between the length of stay associated with high IAP vs. low or standard IAP.

Tabular findings on NMA rank probabilities/league tables for each study outcome are provided in the Appendix Table 2 to 11 in the Supplementary Material, with the treatment ranking for further information.

\section{Discussion}

We conducted an SLR and NMA to compare the effects of three potential levels of IAP used laparoscopic cholecystectomy-namely, low (<12 $\mathrm{mmHg})$, standard $(12-14 \mathrm{mmHg}$ ), and high $(\geq 15 \mathrm{mmHg}$ - —on surgical and patient-reported outcomes and healthcare resource utilization. The SLR included 22 studies.

Our findings suggest that, compared with standard IAP, low IAP was associated with significant reductions in postoperative pain $24 \mathrm{~h}$ post-surgery and in shoulder pain specifically 24 and $72 \mathrm{~h}$ post-surgery. Only one study compared post-operative pain at $24 \mathrm{~h}$ in low vs. high IAP - it showed no statistical difference between the levels. While there were no head-to-head RCT data available on the comparative effects of standard IAP and high IAP with respect to post-operative pain at $24 \mathrm{~h}$, an indirect comparison through a Bayesian NMA suggested there was no statistical difference between the levels, although high IAP had a numerical advantage. There was high heterogeneity $\left(\mathrm{I}^{2} \geq 90 \%\right)$ for the comparison of low with standard IAP; the results of this direct analysis should be interpreted with caution. The same caution should be applied to the indirect result for the 
Fig. 5 Patient outcomes. $C r I$ credible interval, $M A$ meta-analysis, NMA network meta-analysis, $\operatorname{Prob}$ probability

comparison between standard and high IAP. Interestingly, no studies directly compared standard with high IAP levels for any of the nine outcomes of interest.

Our analysis found that, compared with standard IAP, low IAP was associated with a statistically significant, but modest, reduction in the length of inpatient stay. However, for the other outcomes of duration of surgery, conversion to open surgery, acute bleeding, and nausea/vomiting, there were no statistically significant differences between low, standard, and high IAP levels. The data available were limited, or the event rates were low for these outcomes. Therefore, the power to detect significant differences was low, even if IAP levels had a major effect on any of these outcomes.

Our findings on the relative outcomes with low and standard IAP were broadly consistent with those cited in prior SLR reports. The 2013 narrative synthesis by Donatsky et al. [7] (which did not include quantitative analysis) concluded that low IAP in laparoscopic cholecystectomy was associated with lower post-operative shoulder pain at $24 \mathrm{~h}$ compared with standard IAP. In 2014, Hua et al. [8] concluded that low IAP was associated with a significant reduction in post-operative pain compared with standard IAP. However, the inclusion criteria and classification of IAP levels differed between the Hua et al. review [8] and ours. Specifically, while we excluded RCTs that reported duration of surgery only at baseline rather than as a truly comparative surgical outcome and did not report any other relevant outcomes, Hua et al. included such studies. Also, Hua et al. compared only two levels of IAP (low: $7-10 \mathrm{mmHg}$ and standard: $12-15 \mathrm{mmHg}$ ), while our study compared three levels through an NMA. In the review by Donatsky et al. [7], a standardized classification of IAP levels was not adopted; instead, the authors narratively summarized the results based on the IAP levels reported in each included study.

In their MA comparing low $(<12 \mathrm{mmHg}$ ) with standard (12-16 mmHg) IAP in laparoscopic cholecystectomy, Gurusamy et al. found no meaningful differences between the two in duration of surgery, length of stay, mortality, serious adverse events, or conversion to open surgery [1]. While our analysis identified no clear differences in duration of surgery, surgical complications, or conversion to open surgery, it did indicate a reduced length of inpatient stay with low IAP compared with standard IAP.

In a study in patients undergoing laparoscopic surgery, Matsuzaki et al. [32] found that low IAP $(8 \mathrm{mmHg})$, compared with standard IAP (12 $\mathrm{mmHg}$ ) had lower adverse outcomes in molecular levels (e.g., when comparing the expression of the genes that encode inflammatory cytokine signaling molecules). Biologically, animal experiments have
A Post-operative Pain at 24 Hours
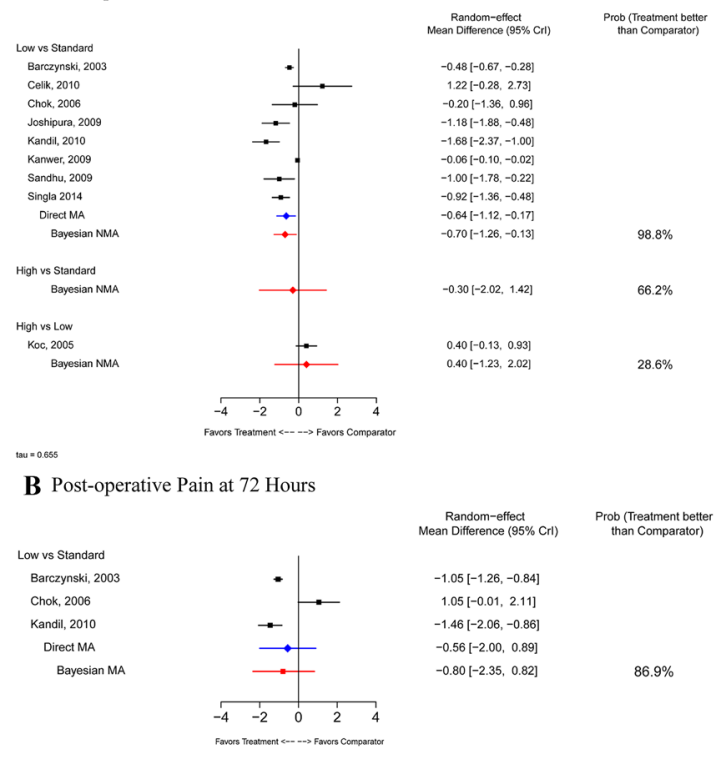

Prob (Treatment better
than Comparator)

$-1.05[-1.26,-0.84]$
$1.05[-0.01,2.11]$

$-1.46[-206,-0.807$

$-1.46[-2.06,-0.86]$

$86.9 \%$

tau $=1.255$

C Shoulder Pain at 24 Hours
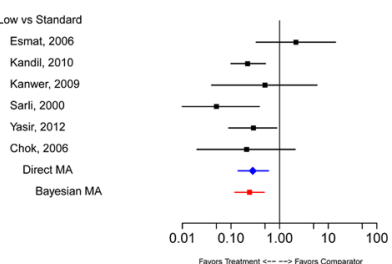

Random-effect
Odds Ratio $99 \%$ CrI

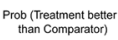

2.17 [0.33, 14.06]

$.22[0.10,0.51]$

0.50 [0.04, 5.86]

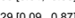

$0.29[0.09,0.87$

$28[014,059]$

$24[1,2009$

$100 \%$

$=0.377$

D Shoulder Pain at 72 Hours

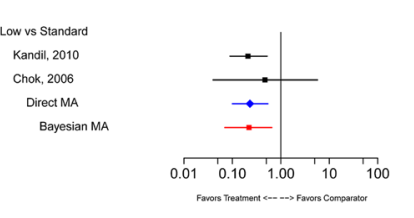

Random-effect
Odds Ratio (95\% Cri)

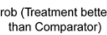

$0.21[0.090 .52]$

$0.47[0.04,5.69]$

$0.23[0.10,0.54]$

$0.22[0.07,0.65]$

$99.6 \%$

$\tan =0.41$

E Acute Bleeding
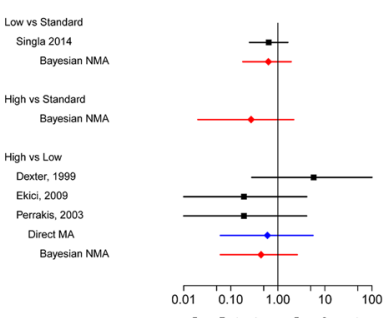

Random-effect
Odds Ratio
$(95 \%$ Crl)

$064[025,1.63]$

$0.63[0.18,1.92]$

$0.27[0.02,2.18]$

$88.4 \%$

$5.78[0.28,120.57]$

$0.190 .01,4.12$

$0.1990 .01,4.09$

$0.44[0.06,258$

$81.8 \%$

$-0.554$

F Nausea or Vomiting

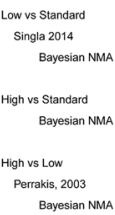

Fixed-effect
Odds Ratiti $(95 \%$ CII)

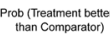

0.46 [0.19, 1.12$]$

$0.45[0.17,1.08]$

$1.03[0.14,10.08$
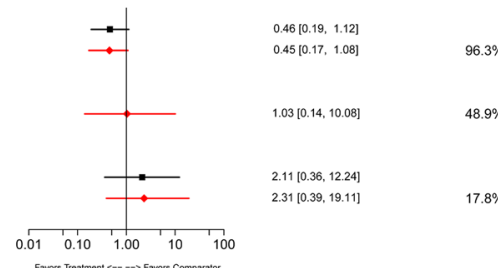

$2.11[0.36,12.24]$

$2.31[0.39,19.11]$

$17.8 \%$ 


\section{A Duration of Surgery}

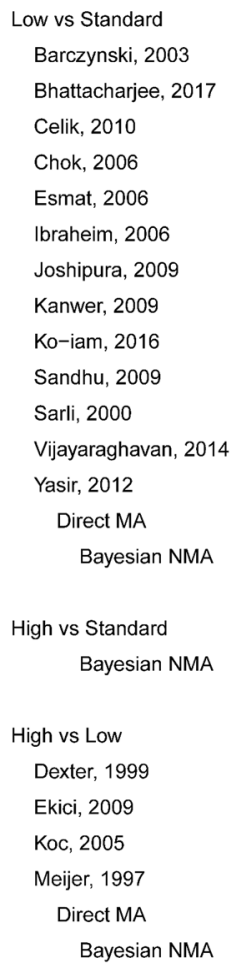

\section{B Length of Hospital Stay (Days)}

Low vs Standard
Barczynski, 2003
Esmat, 2006
Joshipura, 2009
Sandhu, 2009
Sarli, 2000
Yasir, 2012
Direct MA
Bayesian MA

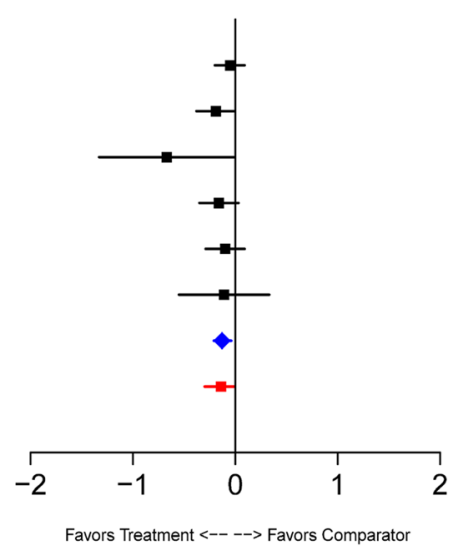

$$
\text { Random-effect }
$$

Mean Difference $(95 \% \mathrm{Crl})$

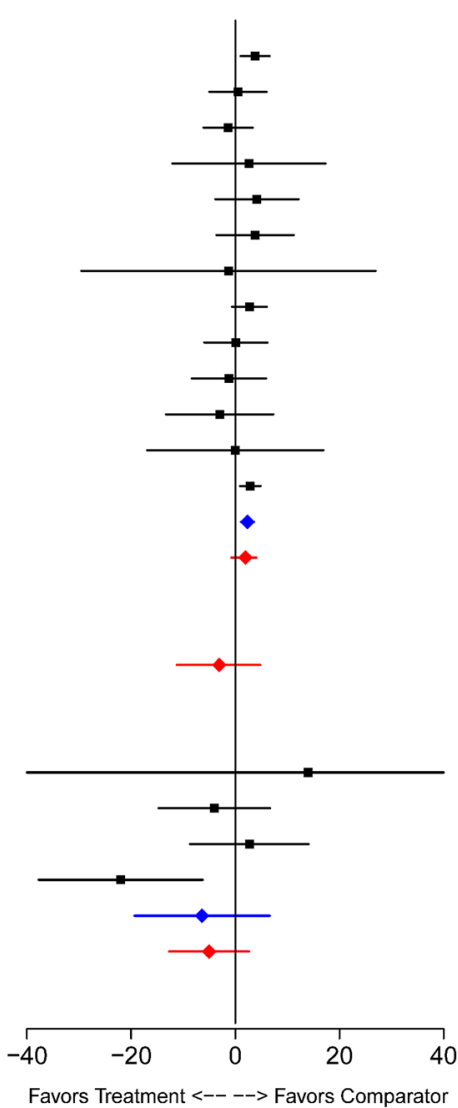

Prob (Treatment better than Comparator)

$$
\begin{aligned}
& 3.80[1.03,6.57] \\
& 0.50[-4.98,5.98] \\
& -1.38[-6.09,3.32] \\
& 2.60[-12.09,17.29] \\
& 4.15[-3.84,12.13] \\
& 3.80[-3.61,11.21] \\
& -1.32[-29.55,26.91] \\
& 2.70[-0.64,6.04] \\
& 0.10[-5.97,6.17] \\
& -1.22[-8.33,5.89] \\
& -3.00[-13.30,7.30] \\
& 0.00[-16.90,16.90] \\
& 2.86 \text { [ } 0.89,4.83 \text { ] } \\
& 2.32[1.09,3.56] \\
& 1.94[-0.76,4.05]
\end{aligned}
$$

$-3.08[-11.26,4.80]$

$14.00[-80.30,108.30]$

$-4.03[-14.70,6.64]$

$2.70[-8.66,14.06]$

$-22.00[-37.73,-6.27]$

$-6.37[-19.36,6.61]$

$-5.02[-12.71,2.64]$
$90.4 \%$

$6.8 \%$

$78.2 \%$<smiles>CCC</smiles> 
categories and the heterogeneity of contributing evidence. Therefore, in attempt to improve upon existing data, we used methodology more likely to provide robust and generalizable data. First, our review was based only on evidence from RCTs. Second, we considered only studies that included data specifically on cholecystectomy to improve homogeneity and comparability. Third, IAP was classified into the three prespecified levels in a clinically meaningful way.

Our review has some limitations. For example, there was substantial heterogeneity among comparisons of low and standard IAP for post-operative pain $\left(\mathrm{I}^{2} \geq 90 \%\right)$. This may have been due to variability in patient characteristics of age, body mass index, or ASA physical status classification, details of which often were not reported across studies. Another limitation was that the studies included patients of Asian/Middle Eastern, European, and African origins, and were conducted in 11 countries. This geographic, ethnic, and cultural diversity could mean that pain and other outcomes might have been perceived differently or that the scales used to report certain outcomes might have been understood differently from study to study. Variation in surgeons' skills and practices, hospital protocols, or hospital resources (e.g., quality of equipment, availability of nurses and other staff during surgery and recovery) could also have contributed to this observed heterogeneity. In particular, length of hospital stay after surgery is likely to have varied with the economies and healthcare systems of the different countries. It is also important to note that we could not assess any inconsistencies between direct and indirect evidence because none of the comparisons had both types available to allow such an evaluation. Lastly, an SLR/NMA is only as robust as the studies contributing to it. This is highly pertinent in our analysis, since most of the included studies had a high risk of bias per the Cochrane Risk of Bias Tool—some study samples were small; the results in all relevant outcomes were not reported consistently; and bias due to selective reporting cannot be ruled out. Given that we analyzed nine outcome scenarios, presenting the certainty of evidence (confidence or robustness of each estimate) for each relative effect of IAP level per each outcome using the Grading of Recommendations Assessment, Development, and Evaluation tool was not feasible. We feel that we have highlighted all concerns and inconsistencies associated with the results from our analyses in detail under the limitations of this SLR.

\section{Conclusion}

Compared with standard IAP, using a low IAP pneumoperitoneum during laparoscopic cholecystectomy may reduce patients' post-operative pain (including shoulder pain) and the length of hospital stay. Our findings are consistent with the existing literature. Therefore, low IAP may be preferred in the clinical practice. However, the data should be interpreted with caution given the high chance of bias and high level of heterogeneity, especially for the post-operative pain outcome. Our review highlights the need for robustly designed and executed, adequately powered RCTs to confirm the findings presented.

Acknowledgements The authors would like to acknowledge Kiran Laxman Ward from Evidera for assisting with manuscript writing. Also, the authors would like to thank Evidera's staffers Evelyn GomezEspinosa, Maria Arregui Rementeria, and Paulina Kazmierska for their contributions on project-related tasks.

Funding This study was sponsored by Merck Sharp \& Dohme Corp, a subsidiary of Merck \& Co., Inc., Kenilworth, NJ, USA. Evidera received funding from Merck Sharp \& Dohme Corp, a subsidiary of Merck \& Co., Inc., Kenilworth, NJ, USA, to conduct this study and prepare the manuscript.

\section{Compliance with ethical standards}

Disclosures Sohan Deshpande, Maria Koufopoulou, Ike Iheanacho, Silvia Rabar, and Binod Neupane are employees of Evidera, which provides consulting and other research services to biopharmaceutical companies. Amit D. Raval, and Lori D. Bash are employees of Merck Sharp \& Dohme Corp, a subsidiary of Merck \& Co., Inc., Kenilworth, NJ, USA. Jay Horrow was an employee of Merck Sharp \& Dohme Corp, a subsidiary of Merck \& Co., Inc., Kenilworth, NJ, US at the time of study conduct. Thomas Fuchs-Buder has received honoraria for lectures from Merck.

Open Access This article is licensed under a Creative Commons Attribution 4.0 International License, which permits use, sharing, adaptation, distribution and reproduction in any medium or format, as long as you give appropriate credit to the original author(s) and the source, provide a link to the Creative Commons licence, and indicate if changes were made. The images or other third party material in this article are included in the article's Creative Commons licence, unless indicated otherwise in a credit line to the material. If material is not included in the article's Creative Commons licence and your intended use is not permitted by statutory regulation or exceeds the permitted use, you will need to obtain permission directly from the copyright holder. To view a copy of this licence, visit http://creativecommons.org/licenses/by/4.0/.

\section{References}

1. Gurusamy KS, Vaughan J, Davidson BR (2014) Low pressure versus standard pressure pneumoperitoneum in laparoscopic cholecystectomy. Cochrane Database Syst Rev. https://doi. org/10.1002/14651858.CD006930.pub3

2. Ozdemir-van Brunschot DM, van Laarhoven KC, Scheffer GJ, Pouwels S, Wever KE, Warle MC (2016) What is the evidence for the use of low-pressure pneumoperitoneum? a systematic review. Surg Endosc 30:2049-2065

3. Boon M, Martini C, Dahan A (2018) Recent advances in neuromuscular block during anesthesia. F1000Research. 7:167 
4. Brull SJ, Kopman AF (2017) Current status of neuromuscular reversal and monitoring: challenges and opportunities. Anesthesiology 126:173-190

5. Kim KS, Lew SH, Cho HY, Cheong MA. (2002) Residual paralysis induced by either vecuronium or rocuronium after reversal with pyridostigmine. Anesth Analg. 95:1656-1660, table of contents

6. Kopman AF, Naguib M (2015) Laparoscopic surgery and muscle relaxants: is deep block helpful? Anesth Analg 120:51-58

7. Donatsky AM, Bjerrum F, Gogenur I (2013) Surgical techniques to minimize shoulder pain after laparoscopic cholecystectomy. A systematic review Surg Endosc 27:2275-2282

8. Hua J, Gong J, Yao L, Zhou B, Song Z (2014) Low-pressure versus standard-pressure pneumoperitoneum for laparoscopic cholecystectomy: a systematic review and meta-analysis. Am J Surg 208:143-150

9. Moher D, Liberati A, Tetzlaff J, Altman DG, Group P (2009) Preferred reporting items for systematic reviews and meta-analyses: the PRISMA statement. BMJ 339:b2535

10. Higgins JPT, Green S. (2011) Cochrane handbook for systematic reviews of interventions version 5.1.0 [updated March 2011]. https ://handbook-5-1.cochrane.org/.

11. Higgins JP, Thompson SG (2002) Quantifying heterogeneity in a meta-analysis. Stat Med 21:1539-1558

12. Kanwer DB, Kaman L, Nedounsejiane M, Medhi B, Verma GR, Bala I (2009) Comparative study of low pressure versus standard pressure pneumoperitoneum in laparoscopic cholecystectomy-a randomised controlled trial. Trop Gastroenterol 30:171-174

13. Ko-Iam W, Paiboonworachat $S$, Pongchairerks $P$, Junrungsee $S$, Sandhu T (2016) Combination of etoricoxib and low-pressure pneumoperitoneum versus standard treatment for the management of pain after laparoscopic cholecystectomy: a randomized controlled trial. Surg Endos 30:4800-4808

14. Meijer DW, Rademaker BP, Schlooz S, Bemelman WA, de Wit LT, Bannenberg JJ, Stijnen T, Gouma DF (1997) Laparoscopic cholecystectomy using abdominal wall retraction. Hemodynamics and gas exchange, a comparison with conventional pneumoperitoneum. Surg Endos 11:645-649

15. Barczynski M, Herman RM (2003) A prospective randomized trial on comparison of low-pressure (LP) and standard-pressure (SP) pneumoperitoneum for laparoscopic cholecystectomy. Surg Endosc 17:533-538

16. Celik AS, Frat N, Celebi F, Guzey D, Kaplan R, Birol S, Memmi N (2010) Laparoscopic cholecystectomy and postoperative pain: is it affected by intra-abdominal pressure? Surg Laparosc Endosc Percutan Tech 20:220-222

17. Chok KS, Yuen WK, Lau H, Fan ST (2006) Prospective randomized trial on low-pressure versus standard-pressure pneumoperitoneum in outpatient laparoscopic cholecystectomy. Surg Laparosc Endosc Percutan Tech 16:383-386

18. Joshipura VP, Haribhakti SP, Patel NR, Naik RP, Soni HN, Patel B, Bhavsar MS, Narwaria MB, Thakker R (2009) A prospective randomized, controlled study comparing low pressure versus high pressure pneumoperitoneum during laparoscopic cholecystectomy. Surg Laparosc Endosc Percutan Tech 19:234-240

19. Kandil TS, El Hefnawy E (2010) Shoulder pain following laparoscopic cholecystectomy: factors affecting the incidence and severity. J Laparoendosc Adv Surg Tech A 20:677-682

20. Koc M, Ertan T, Tez M, Kocpinar MA, Kilic M, Gocmen E, Aslar AK (2005) Randomized, prospective comparison of postoperative pain in low- versus high-pressure pneumoperitoneum. ANZ J Surg 75:693-696

21. Sandhu T, Yamada S, Ariyakachon V, Chakrabandhu T, Chongruksut W, Ko-iam W (2009) Low-pressure pneumoperitoneum versus standard pneumoperitoneum in laparoscopic cholecystectomy, a prospective randomized clinical trial. Surg Endosc 23:1044-1047

22. Singla S, Mittal G, Raghav MRK (2014) Pain management after laparoscopic cholecystectomy-a randomized prospective trial of low pressure and standard pressure pneumoperitoneum. J Clin Diagn Res JCDR 8:92-94

23. Esmat ME, Elsebae MM, Nasr MM, Elsebaie SB (2006) Combined low pressure pneumoperitoneum and intraperitoneal infusion of normal saline for reducing shoulder tip pain following laparoscopic cholecystectomy. World J Surg 30:1969-1973

24. Sarli L, Costi R, Sansebastiano G, Trivelli M, Roncoroni L (2000) Prospective randomized trial of low-pressure pneumoperitoneum for reduction of shoulder-tip pain following laparoscopy. Br J Surg 87:1161-1165

25. Yasir M, Mehta KS, Banday VH, Aiman A, Masood I, Iqbal B (2012) Evaluation of post operative shoulder tip pain in low pressure versus standard pressure pneumoperitoneum during laparoscopic cholecystectomy. Surgeon 10:71-74

26. Dexter SP, Vucevic M, Gibson J, McMahon MJ (1999) Hemodynamic consequences of high- and low-pressure capnoperitoneum during laparoscopic cholecystectomy. Surg Endosc 13:376-381

27. Ekici Y, Bozbas H, Karakayali F, Salman E, Moray G, Karakayali H, Haberal M (2009) Effect of different intra-abdominal pressure levels on QT dispersion in patients undergoing laparoscopic cholecystectomy. Surg Endosc 23:2543-2549

28. Perrakis E, Vezakis A, Velimezis G, Savanis G, Deverakis S, Antoniades J, Sagkana E (2003) Randomized comparison between different insufflation pressures for laparoscopic cholecystectomy. Surg Laparosc Endosc Percutan Tech 13:245-249

29. Bhattacharjee HK, Jalaludeen A, Bansal V, Krishna A, Kumar S, Subramanium R, Ramachandran R, Misra M (2017) Impact of standard-pressure and low-pressure pneumoperitoneum on shoulder pain following laparoscopic cholecystectomy: a randomised controlled trial. Surg Endosc 31:1287-1295

30. Ibraheim OA, Samarkandi AH, Alshehry H, Faden A, Farouk EO (2006) Lactate and acid base changes during laparoscopic cholecystectomy. Middle East J Anaesthesiol 18:757-768

31. Vijayaraghavan N, Sistla SC, Kundra P, Ananthanarayan PH, Karthikeyan VS, Ali SM, Sasi SP, Vikram K (2014) Comparison of standard-pressure and low-pressure pneumoperitoneum in laparoscopic cholecystectomy: a double blinded randomized controlled study. Surg Laparosc Endosc Percutan Tech 24:127-133

32. Matsuzaki S, Jardon K, Maleysson E, D’Arpiany F, Canis M, Botchorishvili R (2012) Impact of intraperitoneal pressure of a $\mathrm{CO} 2$ pneumoperitoneum on the surgical peritoneal environment. Hum Reprod 27:1613-1623

33. Bourdel N, Matsuzaki S, Bazin JE, Pouly JL, Mage G, Canis M (2007) Peritoneal tissue-oxygen tension during a carbon dioxide pneumoperitoneum in a mouse laparoscopic model with controlled respiratory support. Hum Reprod 22:1149-1155

34. Matsuzaki S, Bourdel N, Darcha C, Dechelotte PJ, Bazin JE, Pouly JL, Mage G, Canis M (2009) Molecular mechanisms underlying postoperative peritoneal tumor dissemination may differ between a laparotomy and carbon dioxide pneumoperitoneum: a syngeneic mouse model with controlled respiratory support. Surg Endosc 23:705-714

35. Matsuzaki S, Jardon K, Maleysson E, D'Arpiany F, Canis M, Bazin JE, Mage G (2010) Carbon dioxide pneumoperitoneum, intraperitoneal pressure, and peritoneal tissue hypoxia: a mouse study with controlled respiratory support. Surg Endosc 24:2871-2880

36. Wittich P, Steyerberg EW, Simons SH, Marquet RL, Bonjer HJ (2000) Intraperitoneal tumor growth is influenced by pressure of carbon dioxide pneumoperitoneum. Surg Endosc 14:817-819 
37. Wallace DH, Serpell MG, Baxter JN, O’Dwyer PJ (1997) Randomized trial of different insufflation pressures for laparoscopic cholecystectomy. Br J Surg 84:455-458

38. Zaman M, Chowdhary K, Goyal P (2015) Prospective randomized trial of low pressure pneumoperitoneum for reduction of shoulder tip pain following laparoscopic cholecystectomy: a comparative study. World J Lap Surg 8:13-15
Publisher's Note Springer Nature remains neutral with regard to jurisdictional claims in published maps and institutional affiliations. 